\title{
Effects of refining process on sunflower oil minor components: a review
}

\author{
Alicia Ayerdi Gotor ${ }^{\star}$ and Larbi Rhazi \\ Institut Polytechnique LaSalle Beauvais, 19 rue Pierre Waguet BP30313, 60000 Beauvais, France
}

Received 27 November 2015 - Accepted 4 February 2016

\begin{abstract}
Sunflower oil is well known because of its diversity of fatty acids profiles which allow different uses (food: dressing salads, margarines; nonfood: agrofuel, lubricants). Besides, crude oil contains high amounts of desirable minor components (tocopherols, phytosterols, polyphenols, phospholipids...) that present important nutritional features with a positive impact on human health. The different steps of the refining process have as main objective to remove contaminants and other compounds that could hamper the continuity of the process or alter oil during storage. An indirect consequence of this treatment used to preserve food safety is that micronutriments of interest are also partially eliminated reducing the nutritional quality of the oil. This review describes in the first part the chemical composition of sunflower oil focusing on desirable and undesirable components. In the second part the refining process is detailed following the losses of micronutriments at each step of the process and the elimination of unwanted compounds.
\end{abstract}

Keywords: Sunflower oil / minor components / tocopherols / sterols / refining

\begin{abstract}
Résumé - Effets du procédé de raffinage sur les composants mineurs de l'huile de tournesol : revue. L'huile de tournesol est bien connue pour la diversité de ses profils d'acides gras qui permettent des usages variés (alimentaires huile de table et margarines - ou non alimentaires - agrocarburants et lubrifiants). En outre, l'huile brute contient aussi de grandes quantités de composés mineurs souhaitables (tocophérols, phytostérols, polyphénols, phospholipides...) aux caractéristiques nutritionnelles importantes et à impact positif sur la santé humaine. Les différentes étapes du raffinage ont pour principal objectif d'éliminer les contaminants et les composants susceptibles d'entraver la suite du process ou de provoquer une altération de l'huile au stockage. La conséquence indirecte de ce traitement destiné à préserver la sécurité alimentaire est que les micronutriments d'intérêt sont partiellement éliminés réduisant ainsi la qualité nutritionnelle de l'huile. Dans une première partie, cette revue décrit la composition chimique de l'huile de tournesol en distinguant les composés recherchés et indésirables. La seconde partie examine le procédé de raffinage en suivant les pertes de micronutriments à chaque étape du procès ainsi que l'élimination des produits indésirables.
\end{abstract}

Mots clés : Huile de tournesol / composants mineurs / tocophérols / stérols / raffinage

\section{Introduction}

Sunflower (Helianthus annuus L.) seeds have been object of research to study its nutritional characteristics because of its fatty acids and minor components composition. Sunflower oil represented almost $13 \%$ of the total oilseeds consumed in the world with near 9.5 Millions of tons in 2011 (FAO, 2015) being the 4th more consumed oil. Sunflower oil has an interesting composition in fatty acids (Tab. 1) on its regular form with high

\footnotetext{
^ Correspondence:

alicia.ayerdi-gotor@lasalle-beauvais. fr
}

content in linoleic acid (Regular SO) but also with the other four variants in fatty acids composition: High Oleic Sunflower Oil (HOSO), Mid Oleic Sunflower Oil (MOSO), High Steraric High Oleic Sunflower Oil (HSHOSO) and High Palmitic High Oleic Sunflower Oil (HPHOSO). These four other compositions are interesting for different usages like: biodiesel (Del Gatto et al., 2015), lubricant (Al Mahmud et al., 2013) or its ability to replace hydrogenated fats (Salas et al., 2014). Its oil also contains an important unsaponifiable fraction mainly composed of tocopherols (Vitamin E) and phytosterols, but that also has polyphenols and carotenoids. 
A. Ayerdi Gotor and L. Rhazi: OCL 2016, 23(2) D207

Table 1. Fatty acid composition (\%) of regular sunflower compared to high oleic, mid oleic and high stearic sunflower.

\begin{tabular}{cccccc}
\hline Fatty acid & Regular SO & HOSO & MOSO & HSHOSO & HPHOSO \\
\hline C16:0 & $5.0-7.6$ & $2.6-5.0$ & $4.0-5.5$ & 6 & 29 \\
C18:0 & $2.3-4.0$ & $2-4.0$ & $3.0-5.0$ & 21 & 1.7 \\
C20:0 & $0.1-0.5$ & $0.2-0.5$ & $0.2-0.4$ & 0.2 & $/$ \\
C22:0 & $0.3-1.5$ & $0.5-1.6$ & $0.6-1.1$ & 0.4 & $/$ \\
C24:0 & ND-0.5 & ND-0.5 & $0.3-0.4$ & ND & $/$ \\
C18:1 & $14.0-39.4$ & $75.0-90.7$ & $43.1-71.8$ & 69 & $53-57$ \\
C18:2 & $48.3-74.0$ & $2.1-17.0$ & $18.7-45.3$ & 4 & $2.1-4.3$ \\
\hline
\end{tabular}

Data from Fernández-Moya et al., 2006; Ghazani and Marangoni, 2013; Gunstone, 2011; Marmesat et al., 2008; O’Brien, 2009; ND = Non Detectable; SO = Sunflower Oil; HOSO: High Oleic Sunflower Oil, MOSO = Mid Oleic Sunflower Oil; HSHOSO = High Stearic High Oleic Sunflower Oil; HPHOSO = High Palmitic High Oleic Sunflower Oil

Table 2. Tocopherol contents and composition of several contrasted sunflower oils ( $\mathrm{mg} / \mathrm{kg}$ oil).

\begin{tabular}{cccccc}
\hline & $\alpha$-toco & $\beta$-toco & $\gamma$-toco & $\delta$-toco & Total toco \\
\hline Regular SO & $153-957$ & ND-45 & ND-34 & ND-7 & $176.9-1872$ \\
HOSO & $400-1090$ & $10-35$ & $3-30$ & ND-17 & $450-1120$ \\
MOSO & $488-668$ & $19-52$ & $2-19$ & ND-2 & $509-741$ \\
HPHOSO- $\alpha$ & 826 & $/$ & $/$ & $/$ & $/$ \\
HPHOSO- $\gamma$ & $/$ & $/$ & 808 & $/$ & $/$ \\
IAST-4 & $4(\%)$ & $3(\%)$ & $34(\%)$ & $58(\%)$ & $/$ \\
IAST-5 & $30(\%)$ & $0-77(\%)$ & $/$ & $/$ & $/$ \\
T2100 & $/$ & $/$ & $19-97(\%)$ & $/$ & $/$ \\
\hline
\end{tabular}

Data from Ayerdi Gotor et al., 2007, 2014; Gunstone, 2011; Marmesat et al., 2008; Velasco et al., 2002, 2004; ND = Non Detectable; SO = Sunflower Oil; HOSO: High Oleic Sunflower Oil, MOSO = Mid Oleic Sunflower Oil; HPHOSO = High Palmitic High Oleic Sunflower Oil.

\subsection{Minor components with a nutritional interest}

\subsubsection{Tocopherols}

Tocopherols, also known as Vitamin E, are well known antioxidants molecules naturally found in vegetal oils. There are four forms $\alpha-, \beta$-, $\gamma$ - and $\delta$-tocophérol. $\gamma$-tocopherol has showed the highest in vitro antioxidant activity followed by $\delta$-tocopherol (Kamal-Eldin and Appelqvist, 1996; Seppanen et al., 2010). Whereas $\alpha$-tocopherol presents the highest in vivo activity (Traber and Atkinson, 2007) and it exists daily recommended intakes of up to $16 \mathrm{mg} / \mathrm{d}$ (Institute of Medicine, 2011). Sunflower oil contains a considerable amount of tocopherols but is the oil having the highest amount in $\alpha$ tocopherol (Gunstone, 2011). This content can vary within genotypes (Ayerdi Gotor et al., 2006; Velasco et al., 2002) and environmental conditions during cultivation (Ayerdi Gotor et al., 2006, 2015). The tocopherols composition could also be modified (Velasco et al., 2004) (Tab. 2) but is not linked with the composition of fatty acids (Ayerdi Gotor et al., 2014).

\subsubsection{Phytosterols}

Phytosterols, also known as plant sterols, are a family of compounds which have been studied largely because of their property to reduce the level of cholesterol in blood, but also because of the reduction of the incidence of some cancers (Kritchevsky, 2002). The American National Cholesterol Education Program (Expert panel on detection evaluation and treatment of high blood cholesterol in adults 2001) recommended a daily intake of $2 \mathrm{~g}$ of phytosterol to reduce the low density lipoproteins (LDL cholesterol) in blood. The development of food with added phytosterol has led to regulations on the labeling of these products to avoid an excessive consumption (European Commission, 2013) and a maximum intake of $3 \mathrm{~g} /$ day it has been suggested (European Food Safety Authority, 2008). Sunflower oil has a high content in phytosterols (Gunstone, 2011; Vlahakis and Hazebroek, 2000) (Tab. 3) being $\beta$-sitosterol the main sterol. Phytosterol content is mainly affected by environmental conditions during plant growth (Ayerdi Gotor et al., 2015) and genetics (Aguirre et al., 2014; Fernández-Cuesta et al., 2011) but there is no effect of the modification of the fatty acids profile (Ayerdi Gotor et al., 2014).

\subsubsection{Others terpenoids}

Together with the phytosterols, there are two other terpenoids in sunflower oil, the squalene also a triterpenoid, as the sterols, and the family of carotenoids that are tetraterpenoids. Rao et al. (1998) concluded that the squalene reduces the risk of colon cancer and the serum cholesterol level. Few studies have focused in the variability of squalene in sunflower oil, Merah et al. (2012) reported a variation from 10 to $202 \mathrm{mg} / \mathrm{kg}$ 
A. Ayerdi Gotor and L. Rhazi: OCL 2016, 23(2) D207

Table 3. Phytosterols contents and composition of several contrasted sunflower oils (mg/100 g oil).

\begin{tabular}{ccccccc}
\hline & Campesterol & Stigmasterol & $\beta$-sitosterol & $\Delta^{5}$-Avenasterol & $\Delta^{7}$-Stigmasterol & $\begin{array}{c}\text { Total } \\
\text { phytosterol }\end{array}$ \\
\hline Regular SO & $15.6-65.0$ & $14.4-65.0$ & $120.0-350.0$ & ND-34.5 & $15.6-120$ & $125-765$ \\
HOSO & $8.5-67.6$ & $7.7-67.6$ & $71.4-364.0$ & $2.6-358.8$ & $11.1-124.8$ & $170-520$ \\
MOSO & $9.1-9.6(\%)$ & $9.0-9.3(\%)$ & $56.0-58.0(\%)$ & $4.8-5.3(\%)$ & $6.5-24(\%)$ & - \\
IASP-18 & - & - & - & - & - & 1370 \\
\hline
\end{tabular}

Data from Aguirre et al., 2007, 2014; Gunstone, 2011; ND = Non Detected; SO = Sunflower Oil; HOSO: High Oleic Sunflower Oil, MOSO = Mid Oleic Sunflower Oil.

on a collection of inbred lines. Otherwise, sunflower oil it is not particularly rich in carotenoids with only $1-1.5 \mathrm{ppm}$ of carotenoids (Gunstone, 2011). The major carotenoids in sunflower oil are xantophylls which reach up to $81 \%$ of the total (Rade et al., 2004).

\subsubsection{Phenolic acids}

Phenolic acids have largely been studied because of their antioxidants and neuroprotectives properties (Stevenson and Hurst, 2007). Sunflower oil presents two major polyphenols, namely, vanilic acid with $6.9 \mu \mathrm{g} / 100 \mathrm{~g}$ oil and caffeic acid with $4.9 \mu \mathrm{g} / 100 \mathrm{~g}$ oil. Moreover, there are also small amounts (each one around $1.5 \mu \mathrm{g} / 100 \mathrm{~g}$ ) of p-hydroxybenzoic, $\mathrm{p}$ coumaric, ferulic and sinapic acid (Siger et al., 2008).

\subsubsection{Coenzymes Q9 and Q10}

Coenzymes are isoprenoid chains with 6 to 10 isoprenoid units (number indicated after the Q letter) attached to substituted benzoquinone moiety (Pravast et al., 2010). Few studies have evaluated the content on coenzyme Q9 (CoQ9) and CoQ10 in oils. Rodríguez-Acuña et al. (2008) developed a new method by HPLC MS/MS. They found that sunflower oil had mainly CoQ9 with $101.3 \mathrm{mg} / \mathrm{kg}$ and only $8.7 \mathrm{mg} / \mathrm{kg}$ of CoQ10 in refined oil whereas other studies showed higher amounts of CoQ10 up to $15 \mathrm{mg} / \mathrm{kg}$ in crude oil (Pregnolato et al., 1994). These coenzymes are interesting because they have antioxidant and anti-inflammatory activities (Yang et al., 2015).

\subsection{Other constituents with undesirable functions}

\subsubsection{Phospholipids}

Crude sunflower oil presents high content of phospholipids, which are the major constituents of the biological membranes. The main families of phospholipids found in sunflower oil are phosphatidylcolines, phosphatidylethanolamides, phosphatidylinositols and phosphatidic acids (Gupta, 2002). Sunflowers has mainly hydratable phospholips (Zufarov et al., 2008) but also non hydratable phospholipids, which content could vary in function of the activity of the D phospholipase who is able to convert hydratable onto non hydratable phospholipids in presence of water (Haraldsson, 1983). These molecules have unfavorable effects during the refining process as they can saturate bleaching earths (Taylor, 1993) or induce browning during deodorization (Zamora et al., 2004). This affects the flavor, odor and appearance of the oil, they have, therefore, to be removed during the refining process at the degumming stage (Verleyen, Sosinska et al., 2002). However, polyphenols have a role during oil storage increasing the oxidation stability (Poiana et al., 2009) and could have beneficial effects on human health (Küllenberg et al., 2012).

\subsubsection{Free fatty acids}

The presence of free fatty acids (FFA) in oils may promote oxidation (Frega et al., 1999). The presence of high levels of free fatty acids, or free acidity, is due to wet harvest conditions which promote the action of lipases generating these molecules, as well as moist grains during storage (Beratlief and Iliescu, 1997). In sunflower oil FFA varied from 1.19 to $1.35 \%(\mathrm{w} / \mathrm{w})$ in regular sunflower oil (Kreps et al., 2014), from 0.76 to $1.13 \%$ in HOHPSO (Marmesat et al., 2008) and can reach up to $4 \%$ in HOSO (Moschner and Biskupek-Korell, 2006). FFA are neutralized during the refining process in order to reduce their undesirable effects as undesirable flavor.

\subsubsection{Colorants}

The two most common pigments present in vegetable oils are carotenoids and chlorophylls. Few studies have evaluated the content of those two families of molecules in sunflower oils as they are present in small quantities and they are eliminated during the refining process (at the bleaching step). Topkafa et al. (2013) found that chlorophyll varied from 403 to $1021 \mathrm{ppb}$ in four crude sunflower oils and $\beta$-carotene varied from 1692 to $2803 \mathrm{ppm}$. The refining process reduces the chlorophylls content up to $96 \%$ and $80 \%$ the $\beta$-carotene content (Kreps et al., 2014).

\subsubsection{Wax}

Sunflower seeds contain around $0.9 \%$ of waxes (Carelli et al., 2002) that are present in the hulls. Only a part of the total wax content is eliminated during the winterization step of the refining process, only the small wax chains with less than 


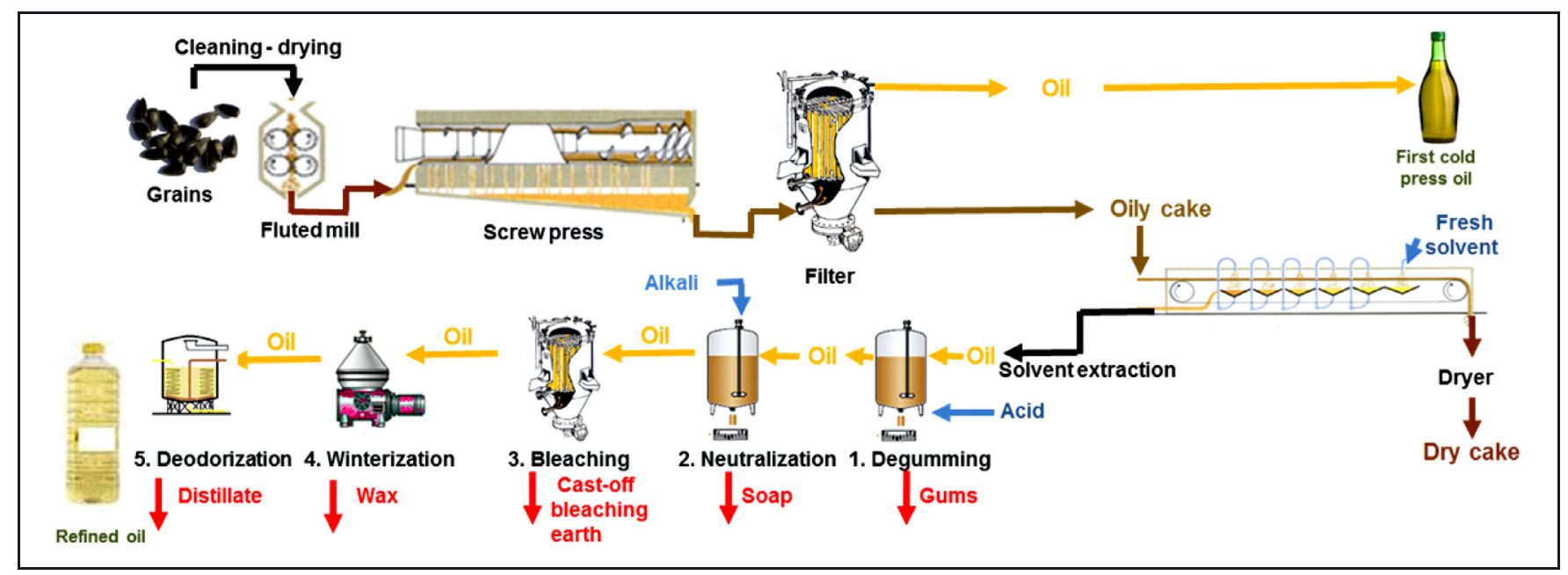

Fig. 1. Extracting and refining steps of sunflower oil.

42 carbons are found in the final product (Carelli et al., 2002). Sunflower has mainly C40 and C41 waxes in cold pressed oil (26.8 and $30.2 \mathrm{mg} / \mathrm{kg}$ ) for a total of $205 \mathrm{mg} / \mathrm{kg}$, whereas in pressed oil C44 was the most abundant $(20.3 \mathrm{mg} / \mathrm{kg})$ followed by C41, C46 and C40 for a total of $409 \mathrm{mg} / \mathrm{kg}$ (Brevedan et al., 2000), in both cases oil has a wax diversity from C36 to C48.

\subsubsection{Trace metals}

Trace metals can act as pro-oxidants wherefore the refining process should diminish their content. In sunflower crude oil we can found Iron at $8.37 \mathrm{mg} / \mathrm{kg}$, cupper at $3.41 \mathrm{mg} / \mathrm{kg}$, calcium at $95.34 \mathrm{mg} / \mathrm{kg}$ and magnesium at $1505.04 \mathrm{mg} / \mathrm{kg}$ (Lamas et al., 2014), and traces of other heavy metals as cobalt, cadmium, chrome, lead; nickel or zink (Pehlivana et al., 2008).

Preserving oil minor components during the refining process is a major issue in world nutrition. In the present review we focus on the resistance of these minor components at each step of the refining process.

\section{Sunflower oil refining}

Sunflower oil mechanical extraction is the first step to obtain crude oil, after filtration cold press oil is obtained. On the other hand the residual oily cake is going to be submitted to a solvent extraction and after five successive stages refined oil is obtained. Figure 1 represents schematically the main steps of sunflower oil extraction and refining. There are five main stages where there is a potential leak of minor components: Degumming, neutralization, bleaching; winterization and deodorization. In industries we can find several adaptations of this simplified schema. When the degumming step or the neutralization step are absent they are called physical or solvent refining respectively.

\subsection{Refined vs. crude oil}

The purpose of refining sunflower oil is to convert the crude oil, which has a high acidity level and/or organoleptic defects, to make it suitable for human consumption. The refining is also aimed at removing contaminants as pesticides and process solvents. Therefore, several refining processing steps are used to remove all undesirable molecules (Fig. 1). Nevertheless, valuable minor components are destroyed and or eliminated with by-products. Generally, several studies have discussed the influence of refining process on the reduction of some minor components present in olive, soybean and rapeseed oil. However, few reports have investigated the effect of each refining step on the total and individual content of each bioactive minor component.

Few studies have evaluated the content of polyphenol and coenzymes in refined oils and none of them have studied the impact of the refining process on all minor components in sunflower oil. The global impact of the refining process observed in different oil matrix was a reduction in these families of molecules. In sunflower oil, we observed a reduction of the total phenolic content from 19.23 to $1.82 \mathrm{mg}$ of gallic acid equivalent/10 g of oil (Kostadinovic-Velickovska and Mitrev, 2013). In rapeseed oil (Kraljić et al., 2015), the loss of polyphenolic compounds was of $63 \%$ during the neutralization, $16 \%$ during the bleaching and was of $67 \%$ during the deodorization step.

In chemical refining process, total tocopherol content gradually declined during overall of process. The reduction in total tocopherols content ranged from 14 to $34 \%$ with an average loss of about 27\% (Alpaslan et al., 2001; Ergönül and Köseoğlu, 2014; Karaali, 1985; Talal et al., 2013; Tasan and Demirci, 2005). Ergönül and Köseoğlu (2014) showed the lowest diminution as they found that the level of total tocopherols decreased from $737 \mathrm{mg} / \mathrm{kg}$ in crude sunflower oil to $633.8 \mathrm{mg} / \mathrm{kg}$ in refined sunflower oil. The highest decline was reported by Tasan and Demirci (2005).

Physical refining process induced a higher reduction of the total tocopherol content compared to chemical refining process. Total tocopherols losses during the physical process varied from 24.6 to $54.8 \%$ with an average loss of $41 \%$ (Alpaslan et al., 2001; Kreps et al., 2014; Tasan and Demirci, 2005). Differences in the amount reduction depend on the nature of sunflower cultivars (i.e.: HOSO or regular SO) and the severity of the process conditions such as temperature and steam flow. 
Phytosterol content and composition changes during the hole refining process were evaluated by Verleyen, Forcades et al. (2002) who found that the process modified the phytosterol composition by increasing the esterified sterols passing from $28.6 \%$ in bleached oil to $40 \%$ in the refined oil (after the deodorization) of the total sterol content. Karaali (1985) determined in chemically refined sunflower oil a decrease of $60.3 \%$ on total phytosterols, with the highest loss during the physical neutralization step.

The level of squalene was found to decrease continuously during all refining steps (Nergiz and Çelikkale, 2011). Total average reduction for sunflower seed oil samples during refining process was $32.9 \%$. The level was about $13.8 \mathrm{mg} / 100 \mathrm{~g}$ in crude sunflower oil and about $9.2 \mathrm{mg} / 100 \mathrm{~g}$ in refined sunflower oil.

\subsection{Degumming}

The main objective of the degumming step is to remove phospholipids (Segers and van de Sande, 1990) as they lead to a dark oil color and promote off-flavors in processed oils. The degumming could be made with water when oil contains hydratable phospholipids or with a previous treatment with an acid like phosphoric or citric acid when oil contains nonhydratable phospholipids (Segers and van de Sande, 1990; Zufarov et al., 2008). Both treatments convert hydratable and nonhydratable forms into hydrated gums. The water degumming process permits to remove about $83 \%$ of total phospholipids from solvent extracted sunflower oil (Brevedan et al., 2000). During the refining process metals are removed, acid degumming reduces the content of calcium and magnesium of 88 and $90 \%$ (Zufarov et al., 2008), and the iron content is reduced from 4.4 to $3.3 \mathrm{ppm}$ (Karaali, 1985). FFA content is reduced up to $82 \%$ passing from 1.24 to $0.23 \%$ (w/w) in a combined degummingneutralization step (TOP, also called total degumming process) (Kreps et al., 2014). But it decreased only 20\% from 1.03 to 0.83 (\% g oleic acid) in a classic degumming step (Karaali, 1985). Chlorophylls are reduced from 5.62 to 4.63 (mg/kg pheophytin a) in HOSO and from 4.32 to 3.56 in regular SO in acid degumming (Kreps et al., 2014).

In addition, the degumming step could be done using enzymatic treatment (Carelli et al., 2002; Lamas et al., 2014). Phospholipid content is reduced up to $97.8 \%$ while phosphorus content is decreased up $99.4 \%$ (Lamas et al., 2014). About $81.2 \%$ and $93 \%$ of the calcium and magnesium content respectively, is removed from the crude sunflower oil during enzymatic degumming (Lamas et al., 2014).

This degumming step also affects the content of desirable molecules, tocopherol content is reduced between 6.6 to $8.4 \%$ of the total content in regular SO and HOSO respectively (Kreps et al., 2014) but there is no modification in the composition (Tab. 4). These reductions are in agreement with other reported losses (Tasan and Demirci, 2005). These authors found losses of $6 \%$ in total tocopherol content during degumming stage of the physical refining process. Karaali (1985) showed a lower reduction in the total tocopherol content, in about 4\%. Karaali (1985) also studied the effect of chemical degumming step on sterol content in sunflower oil and found a decrease of $22.4 \%$ in total sterol content with equivalent results on individual sterols, except for 47 -Avenasterol which increased its relative content $50 \%$.

Reduction in minor components contents during degumming stage could be attributed to acid catalyzed hydrolysis (Verleyen et al., 2001). No data of the content of these components in the produced gum have been reported. Therefore, losses could not be attributed to liquid-solid partitioning of minor components into the gum.

\subsection{Neutralization}

Oil alkali neutralization is also known as deacidification. It is an important step in the edible oil refining process and aims to remove FFA in oil. It neutralizes free fatty acids in the oil using caustic soda and potash, also decomposes pigments, it eliminates phosphorus compounds, trace metals, proteins and oxidizing materials. Alkali treatment converts the acids into soaps (Hendrix, 1990). These soaps are easily removed by decantation or by centrifugation. This step is only used in the chemical refining process.

Few investigations have discussed the effect of oil neutralization step on minor constituents of refined sunflower oil. Four to $16 \%$ losses in total tocopherol level were observed between crude and neutralized oil. Alpasan et al. (2001) analyzed total and individual tocopherol contents of sunflower oil, processed either by chemical refining or physical refining methods. About $4.7 \%$ of loss in total tocopherol content occurred during chemical neutralization (Tab. 4). They reported a significant decrease of all tocopherols but $63 \%$ of the reduction was due to $\alpha$-tocopherol. Higher elimination of the total tocopherol content has been obtained during chemical neutralization step (Karaali, 1985; Naz et al., 2011). Karaali (1985) showed a significant loss of $11.8 \%$ while Naz et al. (2011) presented losses of $16 \%$ in the total sunflower tocopherol content. More recently, Talal et al. (2013) showed a significant decrease in the level of total tocopherols content in sunflower oil during the degumming and alkali neutralizing step. Results of their study indicated a loss of about $10 \%$ in total tocopherol amount.

The reduction in the total tocopherol content during the oil neutralization is in agreement with the results of several reported studies on vegetable oils, according to which caustic soda treatment affected the tocopherol level of oils (Ferrari et al., 1996; Karaali, 1985; Tasan and Demirci, 2005). The decline of tocopherols may be due to the fact that tocopherols are unstable in the presence of long contact time with air and alkali and are oxidized to tocoquinones (Tasan and Demirci, 2005).

In addition, chemical treatment do not have similar impact on individual tocopherol content since a loss of $\alpha-, \beta$-, $\gamma$ - and $\delta$-tocopherols of $3,26,24,16 \%$, respectively, was observed (Alpaslan et al., 2001).

A significant decline in the total sterol content in vegetable oil has been reported during the chemical neutralization step (Gutfinger and Letan, 1974), which is attributed to a liquid-liquid partitioning of phytosterols into the soapstock (Serani and Piacenti, 1992). Neutralization process caused in oils $29.3 \%$ losses of total sterols. Results of Ruiz-Méndez et al. (2011) confirm that an important quantity of removed sterols 
A. Ayerdi Gotor and L. Rhazi: OCL 2016, 23(2) D207

Table 4. Losses (\%) of minor components during each step pf the refining process.

\begin{tabular}{|c|c|c|c|c|}
\hline Processing stages & $\begin{array}{c}\text { Total } \\
\text { Tocopherols }\end{array}$ & $\begin{array}{c}\text { Total } \\
\text { Phytosterols }\end{array}$ & Squalene & Polyphenols \\
\hline \multicolumn{5}{|c|}{ Chemical refining process } \\
\hline Degumming & 4 & 22.4 & $\mathrm{ND}^{*}$ & ND \\
\hline Neutralization & $3.9-14.7$ & 29.3 & ND & ND \\
\hline Bleaching & $5.85-7.9$ & ND & ND & ND \\
\hline Winterization & $0.6-4.6$ & 5.2 & ND & ND \\
\hline Deodorization & $3.6-15.7$ & 3.4 & ND & ND \\
\hline Total loss & $14-34$ & 60.3 & ND & $90.5 \%$ \\
\hline \multicolumn{5}{|c|}{ Physical refining process } \\
\hline Degumming & $6-8.4$ & ND & 6.9 & ND \\
\hline Bleaching & $3.5-15.8$ & ND & 5.3 & ND \\
\hline Winterization & $0.8-5.8$ & ND & 4 & ND \\
\hline Deodorization & $20.2-25.7$ & ND & 16.9 & ND \\
\hline Total loss & $24.6-54.8$ & ND & 33.1 & ND \\
\hline
\end{tabular}

*ND = Not available data. Data from: (Alpaslan et al., 2001; Ergönül and Köseoğlu, 2014; Karaali, 1985; Kreps et al., 2014; Nergiz and Çelikkale, 2011; Talal et al., 2013; Tasan and Demirci, 2005; Verleyen, Forcades et al., 2002).

is found in soapstocks obtained from sunflower oil. Authors demonstrated the influence of alkali concentration and temperature used during neutralization on the total sterol content.

A significant reduction of the total polyphenol content which represents a loss of near $25 \%$ of the initial content during this neutralization step was found by Karaali (1985).

Nergiz and Çelikkale (2011) have evaluated the effect of the refining steps on the squalene content of some vegetable oils and found significant reduction in the squalene content after the neutralization/physical refining step. The reduction during this stage of refining was found to be $7 \%$ as compared to crude sunflower oil.

\subsection{Bleaching}

This third step of the oil refining process has as main objective to remove coloring pigments from carotenoids, chlorophylls, and related compounds that catalyze the oxidation of the oil by reacting with light, by using bleaching earths that can be acid activated or coupled with activated carbon to increase the adsorption power and diminish the quantities used (Anderson, 2005; Topkafa et al., 2013). Bleaching earth are also adsorbing residual soaps, phospholipids and other polar lipids (Anderson 2005). Although bleaching generally improves crude oil quality with respect to color, initial and aged flavor, along with oxidative stability, this refining step also has other effects. Some of them are desirable; others are undesirable as the isomerization of the triglycerides (Anderson, 2005). FFA content do not vary significantly during this step in sunflower oil (Kreps et al., 2014) but this step could lead to an increase in FFA in other oils. Chlorophylls are eliminated up to $96 \%$ in both $\mathrm{HOSO}$ and regular SO where the bleaching conditions were: temperature $90{ }^{\circ} \mathrm{C}, 0.59 \% \mathrm{w} / \mathrm{w}$ bleaching clay (TAIKO, type: Classic $1 \mathrm{G}$, Malaysia) with mechanical stirring was used at vacuum $13 \times 10^{3} \mathrm{~Pa}$ for $30 \mathrm{~min}$
(Kreps et al., 2014) and carotenoids around $77 \%$ of the initial value (Rade et al., 2004). The decreases in total tocopherol contents due to bleaching step have been largely studied (Alpaslan et al., 2001; Ergönül and Köseoğlu 2014; Kreps et al., 2014; Tasan and Demirci, 2005). The average reduction is approximately 8\% (Alpaslan et al., 2001; Kreps et al., 2014; Tasan and Demirci, 2005). Tasan and Demirci (2005) showed declines of 7.2 and $7.6 \%$ in total tocopherol contents for chemical and physical refining process respectively but there is no indication of the bleaching conditions used. Alpaslan reported the lowest percentage of losses during physical process but also the bleaching conditions were no described. Ergönül and Köseoğlu, $2014\left(90{ }^{\circ} \mathrm{C}, 20 \mathrm{~min}, 1 \%\right.$ of activated earth w/w) showed $6 \%$ losses. Kreps et al. (2014) reported losses of $14.9 \%$ in HOSO and $15.8 \%$ in regular sunflower oil during this refining step without change in the composition of tocopherol isomers. Naz et al. (2011) reported the highest losses of $38.2 \%$ of the total tocopherol content (with unspecified bleaching conditions). These reductions during the process of bleaching are due to the complexation of tocopherols with molecules of bleaching clay. The alkalinity and acidity of bleaching clay may damage tocopherol molecules. It has been demonstrated that acid activated bleaching clay can catalyze tocopherol esterification. The acid can also play a role in protonation of tocopherol to produce oxonium ions (McMurry, 2004; Taylor, 2005).

No study has evaluated the impact of bleaching stage on the sunflower's sterols. In other oils total sterol content was slightly reduced in cotton seed oil $(8.7 \%$ according to El-Mallah et al. (2011). In other study authors observed a reduction of $1.3,8$ and $18.5 \%$ in corn, soybean and rapeseed respectively in the total sterol content (Ferrari et al., 1996). A deeper analysis on sterol evolution during the refining process was conducted by Verleyen, Sosinska et al. (2002). They showed a differentiated behavior depending on the oil matrix for the evolution of esterified and free sterols. Corn oil presented an increase of up to $3 \%$ of free sterols and a decrease 
of $5 \%$ of esterified sterols. In palm oil they observed no difference on esterified sterols and a decrease of $16 \%$ on free sterols.

Last, $6 \%$ of the squalene content is lost during this bleaching step (Nergiz and Çelikkale, 2011).

\subsection{Winterization}

Winterizationalso called dewaxing has as main objective to eliminate long chain waxes (with carbon number higher than C42) (Brevedan et al., 2000) and saturated triglycerides by reducing the oil's temperature to $6-8{ }^{\circ} \mathrm{C}$ and eliminating the solid particles, for instance, by filtration (Ruiz Mendez et al., 2013). Winterization is the step that reduces the least the minor compounds and particularly tocopherols. In sunflower oil, the reduction in total tocopherol content range from 0.6 to $5.8 \%$ with an average of about $2.4 \%$ and a variation coefficient between studies of about $76 \%$. These variations are due to the refining process used and the nature of sunflower. Kreps et al. (2014) found a loss of 5.8\% in HOSO and of $2.9 \%$ in regular SO during the process of winterization. In that study, authors explained the decline of tocopherols in winterized oil by interactions between detergent and tocopherols and their removal with waxes.

The winterization has no impact on chlorophylls and reduces $18 \%$ of the content of $\beta$-carotene in both regular and HOSO (Kreps et al., 2014). Karaali (1985) found that the total sterol content diminish in $5.2 \%$ that came from an equivalent reduction of each individual sterol except campesterol, its content was reduced $11 \%$ and $\Delta 7$ avenasterol which increased nearly $35 \%$.

Nergiz and Çelikkale (2011) investigated the changes in the amount of squalene in different vegetable oils during the refining process and found that the smallest reduction of squalene was caused during the winterization. The average reduction was found to be $4 \%$.

\subsection{Deodorization}

In the edible oil processing, deodorization is the final key step used to remove the off flavors generated during the previous refining steps as oxidation products such as: hydroperoxides, aldehydes, ketones and epoxides, and pulling out volatile components as FFA or contaminants (Akterian, 2009). At the end of this stage, the taste, odor, flavor, color and stability of the oil is improved. During deodorization oil is subjected to high temperatures, to a stripping stream and pressure for a given duration aimed to the optimization of the elimination of undesirable substances, but preserving minor components (leaving at least $80 \%$ of them) and reducing the creation of trans fatty acids or oxidation products (Martinčič et al., 2008).

Changes in the content of total tocopherols during this stage are tightly related to the conditions of oil treatment. Physical refining process causes the highest decline. Therefore, losses in total tocopherols content range from 3.7 to $15.7 \%$ during chemical refining process (Alpaslan et al., 2001; Ergönül and Köseoğlu, 2014; Karaali, 1985; Talal et al., 2013; Tasan and Demirci, 2005) while the reported values of reductions during physical refining process are between $21.2 \%$ and 25.7\% (Alpaslan et al., 2001; Kreps et al., 2014; Tasan and Demirci, 2005). According to these reports, the deodorization stage is the highest reducing stage for tocopherols. The percentages of losses due to this step range from 26.2\% (Ergönül and Köseoğlu, 2014) to $86.3 \%$ (Alpaslan et al., 2001) with an average of about $48.6 \%$. In order to decrease the effect of this step on minor components, studies have been done to optimize deodorization conditions. To reduce the losses and preserve up to $90 \%$ of the total tocopherol and phytosterol content, Martinčič et al. (2008) found in HOSO that the conditions during this deodorization step should be: temperature under $235^{\circ} \mathrm{C}$, with a pressure of 3 mbar and a sparge steam between 2.25 and $1 \%$. Reducing the temperature during the process reduces the losses, but increases the FFA content and reduces the organoleptic value of the oil. During the deodorization step in the oil there is formation of steradienes, that are the dehydrated form of sterols caused by high temperatures and acid conditions (in physical refining) (Verleyen, Szulczewska et al., 2002) reducing the content of free sterol. In sunflower oil Karaali (1985) observed a reduction of $3.4 \%$ of total sterol content with higher losses of campesterol and stigmasterol (12\% and $15 \%$ respectively) and just $3 \%$ in $\beta$-sitosterol, relatively $\Delta 5$-avenasterol and $\Delta 7$-stigmasterol increased their content to 9 and $7 \%$ respectively. Squalene is lost up to $7 \%$ in the deodorization process (Nergiz and Çelikkale, 2011). Carotenoids suffer a supplementary reduction of between $8 \%$ and $28 \%$ of the initial content during this step, reaching a final content equivalent to $15-20 \%$ of the initial value in regular SO and 25\% in HOSO (Kreps et al., 2014; Rade et al., 2004).

Chlophylls are slightly reduced during this step (Kreps et al., 2014) to a minimal value of $0.18-0.21 \mathrm{mg} / \mathrm{kg}$ pheophytin a (regular and HOSO respectively) that represented $4 \%$ of the initial value on crude sunflower oil which represented a supplementary elimination of $15 \%$ during this step.

Deodorization step also influence the content of squalene in sunflower oil (Nergiz and Çelikkale, 2011). The last report showed that most of the losses of squalene $(17 \%)$ occurred during this refining step.

Decline of minor components in deodorized oil is in part due to removal of these molecules during injection of heated steam. Therefore, valuable minor components such as tocopherols, tocotrienols, phytosterols, squalene and hydrocarbons are stripped. Then, they are found in the deodorizer distillate which is the most important by-product of edible oil refining. Naz et al. (2011) studied the chemical characterization of sunflower oil deodorizer distillates and found significant amounts of sterols, squalene and tocopherols. They showed that total sterols in deodorized distillate sunflower were present at the concentration of 13.9-14.2\% and total tocopherols and hydrocarbons were estimated at average percentages of 6.5 and 16.5, respectively.

\section{Conclusions}

During the refining process sunflower oil loses considerable amounts of minor components that have interesting nutritional and health related characteristics. Several studies have been done to reduce the loss of micronutriments and preserve final oil quality and nutritional characteristics, 
for example by using pre heating with microwave (Veldsink et al., 1999; Zacchi and Eggers, 2008) which increases the final tocopherol and polyphenols content; or, modifying the temperatures during the deodorization step (Martinčič et al., 2008) that reduces the losses of phytosterols and tocopherols. However losses persist, but the residual products of this refining process are partially recovered to be used in other industries like cosmetic industry (tocopherols and phytosterols), gums in the form of lecithin is included in several food products instead of soybean lecithin. Challenges are: (i) to find cultivars with high levels in these minor components, as in the case of sterols (Velasco et al., 2014), (ii) To evaluate the possibility and developing new commercial varieties with these new traits continuing efforts already done (Ayerdi Gotor et al., 2008), (iii) To evaluate the impact at each step of the refining process of minor nutriments like coenzymes or $\beta$-carotene, (iv) To find the optimal refining conditions at each step, to preserve the maximum of all these nutriments. The last goal of this essential research is to increase the amount of the mentioned minor components after the refining process which has an important repercussion in the nutritional and economical value of the obtained oil.

\section{References}

Aguirre MR, Velasco J, Victoria Ruiz-Méndez M. 2014. Characterization of sunflower oils obtained separately by pressing and subsequent solvent extraction from a new line of seeds rich in phytosterols and conventional seeds. OCL 21: D605.

Akterian S. 2009. Modelling and evaluating the batch deodorization of sunflower oil. J. Food Erg. 91: 29-33.

Al Mahmud KAH, Zulkifli NWM, Masjuki HH, et al. 2013. Working temperature effect of A-C: H/A-C: $\mathrm{H}$ and steel/steel contacts on tribo properties in presence of sunflower oil as a bio lubricant. $J$. Food Erg. 68: 550-557.

Alpaslan M, Tepe S, Simsek O. 2001. Effect of refining processes on the total and individual tocopherol content in sunflower oil. Int. J. Food Sci. Technol. 36: 737-739.

Anderson DA. 2005. Primer on oils processing technology. In: Shahidi F, ed., Bailey's industrial oil and fat products. New Jersey (USA), Vol. 5.

Ayerdi Gotor A, Berger M, Labalette F, Centis S, Daydé J, Calmon A. 2006. Étude de la variation des teneurs et compositions des composés mineurs dans l'huile de tournesol au cours du développement du capitule : Partie I - Tocophérols. OCL 13: 206-212.

Ayerdi Gotor A, Farkas E, Berger M. et al. 2007. Determination of tocopherols and phytosterols in sunflower seeds by NIR spectrometry. Eur. J. Lipid Sci. Technol. 109: 525-530.

Ayerdi Gotor A, Berger A, Labalette F, Centis S, Daydé J, Calmon A. 2008. Estimation of breeding potential for tocopherols and phytosterols in sunflower. In: 17th International Sunflower Conference. Junta de Andalucía, Córdoba, Spain, pp: 555-560.

Ayerdi Gotor A, Berger M, Labalette F, Centis S, Daydé J, Calmon A. 2014. Oleic conversion effect on tocopherols and phytosterols content in sunflower oil. Phyton 83: 319-324.

Ayerdi Gotor A, Berger M, Labalette F, Centis S, Daydé J, Calmon A. 2015. Variability and relationships between fatty acids, tocopherols and phytosterols content in sunflower cultivars
(Helianthus annuus) from a three years multi-local study. Int. J. Exp. Bot. 84: 14-25.

Beratlief C, Iliescu H. 1997. Highlights of proprer sunflower seed storage. Helia. 20: 121-132.

Brevedan MIV, Carelli AA, Crapiste GH. 2000. Changes in composition and quality of sunflower oils during extraction and degumming. Grasas Aceites 51: 417-423.

Carelli A, Frizzera L, Forbito P, Crapiste G. 2002. Wax composition of sunflower seed oils. J. Am. Oil Chem. Soc. 79: 763-768.

Del Gatto A, Mengarelli C, Foppa Pedretti E. et al. 2015. Adaptability of sunflower (Helianthus annuus L.) high oleic hybrids to different Italian areas for biodiesel production. Ind. Corp. Prod. 75, Part A: 108-117.

El-Mallah MH, El-Shami SM, Hassanien MMM, Abdel-Razek AG. 2011. Effect of chemical refining steps on the minor and major components of cottonseed oil. Agric. Biol. J. N. Am. 2: 341-349.

Ergönül PG, Köseoğlu O. 2014. Changes in $\alpha-, \beta$-, $\gamma$ - and $\delta$ tocopherol contents of mostly consumed vegetable oils during refining process. CyTA - J. Food 12: 199-202.

European Commission. 2013. Amending Regulation (EC) No $608 / 2004$ concerning the labeling of foods and food ingredients with added phytosterols, phytosterol esters, phytostanols and/or phytostanol esters. Commission Regulation (EU) no 718/2013 of 25 July 2013, Official Journal of the European Union, pp. 49-50.

European Food Safety Authority. 2008. Food and beverages with added plant sterols. The Efsa Journal, Parma, pp. 1-21.

Expert panel on detection evaluation and treatment of high blood cholesterol in adults. 2001. Executive summary of the third report of the National Cholesterol Education Program (NCEP) expert panel on detection, evaluation, and treatment of high blood cholesterol in adults (Adult treatment panel III). 285: 2486-2497.

FAO. 2015. FAOSTAT Database. http://faostat3.fao.org/download/ FB/CC/E Food and Agriculture Organization.

Fernández-Moya V, Martínez-Force E, Garcés R. 2006. Lipid characterization of a high-stearic sunflower mutant displaying a seed stearic acid gradient. J. Agric. Food Chem. 54: 3612-3616.

Fernández-Cuesta A, Velasco L, Fernández-Martínez JM. 2011. Phytosterols in the seeds of wild sunflower species. Helia 34: 31-38.

Ferrari RAP, Schulte E, Esteves W, Brühl L, Mukherjee KD. 1996. Minor constituents of vegetable oils during industrial processing. J. Am. Oil Chem. Soc. 73: 587-592.

Frega N, Mozzon M, Lercker G. 1999. Effects of free fatty acids on oxidative stability of vegetable oil. J. Am. Oil Chem. Soc. 76: 325-329.

Ghazani SM, Marangoni AG. 2013. Minor components in canola oil and effects of refining on these constituents: A review. J. Am. Oil Chem. Soc. 90: 923-932.

Gunstone FD. 2002. Vegetable oils in food technology - composition, properties and uses. Oxford (UK) Whiley-Blackwell Publishing Ltd.

Gupta MK. 2002. Sunflower oil. In: Gunstone FD, ed., Vegetable oils in food technology: Composition, properties and uses. Oxford (UK): Wiley-Blackwell, pp. 125-156.

Gutfinger T, Letan A. 1974. Quantitative changes in some unsaponifiable components of soya bean oil due to refining. J. Sci. Food Agric. 25: 1143-1147.

Haraldsson G. 1983. Degumming, Dewaxing and Refining. J. Am. Oil Chem. Soc. 60: 251-256. 
Hendrix B. 1990. Neutralization I. Theory and practice of conventional caustic (NAOH) refining. In: Erickson DR, ed., Edible fats and oils processing: basic principles and modern practices. Illinois (USA): American Oil Chemists' Society, p. 449.

Institute of Medicine. 2011. Dietary Reference Intakes: Recommended Intakes for Individuals. Agriculture USDo, p. 8 .

Kamal-Eldin A, Appelqvist LA. 1996. The chemistry and antioxidant properties of tocopherols and tocotrienols. Lipids 31:671-701.

Karaali A. 1985. The effects of refining on the chemical composition of Turkish sunflower seed oil. Eur. J. Lipid Sci. Technol. 87: 112117.

Kostadinovic-Velickovska S, Mitrev S. 2013. Characterization of fatty acid profile, polyphenolic content and antioxidant activity of cold pressed and refined edible oils from Macedonia. J. Food Chem. Nutr. 1: 1-6.

Kraljić K, Škevin D, Barišić L, Kovačević M, Obranović M, Jurčević I. 2015. Changes in 4-vinylsyringol and other phenolics during rapeseed oil refining. Food Chem. 187: 236-242.

Kreps F, Vrbiková L, Schmidt Š. 2014. Influence of industrial physical refining on tocopherol, chlorophyll and beta-carotene content in sunflower and rapeseed oil. Eur. J. Lipid Sci. Technol. 116: 1572-1582.

Kritchevsky D. 2002. Phytosterols in human health. In: Mackey K, ed., Nutritional toxicology. 2. New York: Taylor \& Francis, pp. 173-189.

Küllenberg D, Taylor LA, Schneider M, Massing U. 2012. Health effects of dietary phospholipids. Lipids Health Dis. 11: 3.

Lamas DL, Crapiste GH, Constenla DT. 2014. Changes in quality and composition of sunflower oil during enzymatic degumming process. Lebensmittel-Wissenschaft und-Technologie 58: 71-76.

Marmesat S, Velasco L, Ruiz-Méndez MV, Fernández-Martínez JM, Dobarganes C. 2008. Thermostability of genetically modified sunflower oils differing in fatty acid and tocopherol compositions. Eur. J. Lipid Sci. Technol. 110: 776-782.

Martinčič V, Golob J, de Greyt W, et al. 2008. Optimization of industrial-scale deodorization of high-oleic sunflower oil via response surface methodology. Eur. J. Lipid Sci. Technol. 110: 245-253.

McMurry JE. 2004. Organic chemistry, 6th ed. Thomson learning company, USA.

Merah O, Langlade N, Alignan M, et al. 2012. Genetic analysis of phytosterol content in sunflower seeds. Theor. Appl. Genet. 125: 1589-1601.

Moschner CR, Biskupek-Korell B. 2006. Estimating the content of free fatty acids in high-oleic sunflower seeds by near-infrared spectroscopy. Eur. J. Lipid Sci. Technol. 108: 606-613.

Naz S, Sherazi STH, Talpur F. 2011. Changes of total tocopherol and tocopherol species during sunflower oil processing. J. Am. Oil Chem. Soc. 88: 127-132.

Nergiz C, Çelikkale D. 2011. The effect of consecutive steps of refining on squalene content of vegetable oils. J. Food Sci. Technol. 48: 382-385.

O'Brien RD (ed.). 2009. Fats and oils. Formulation and processiong for applications. Boca Raton: CRC Press.

Pehlivana E, Arslanb G, Godec F, Altuna T, Özcand MM. 2008. Determination of some inorganic metals in edible vegetable oils by inductively coupled plasma atomic emission spectroscopy (ICP-AES). Grasas y Aceites 59: 239-244.
Poiana MA, Alexa E, Moigradean D, Popa M. 2009. The influence of the storage conditions on the oxidative stability and antioxidant properties of sunflower and pumpkin oil. In: Proceedings of the 44th Croatian \& 4th International Symposium of Agriculture, Opatija, Croatia, 16-20, pp. 449-453.

Pravast I, Zmitek K, Zmitek J. 2010. Coenzyme Q10 contents in foods and fortification Strategies. Crit. Rev. Food Sci. Nutr. 50: 269-280.

Pregnolato P, Maranesi M, Mordenti T, Turchetto E, Barzanti V, Grossi G. 1994. Coenzyme Q10 and Q9 content in some edible oils. RISG 71: 503-505.

Rade D, Mokrovčak Ž, Štrucelj D, Škevin D, Neđeral S. 2004. The effect of processing conditions on the nontriacylglycerol constituents of sunflower oil. Acta Alimentaria 33: 7-18.

Rao CV, Newmark HL, Reddy BS. 1998. Chemopreventive effect of squalene on colon cancer. Carcinogenesis 19: 287-290.

Rodríguez-Acuña R, Brenne E, Lacoste F. 2008. Determination of coenzyme Q10 and Q9 in vegetable oils. J. Agric. Food Chem. 56: 6241-6245.

Ruiz Méndez MV, Aguirre-González MR, Dobarganes MC. 2011. Influence of neutralization stage conditions on soapstock phytosterol content. In: Society AOC, ed., World Conference on Oilseed Processing, Fats \& Oils Processing, Biofuels \& Applications, Turkey.

Ruiz Mendez MV, Aguirre Gonzalez MR, Marmesat S. 2013. Olive oil refining process. In: Aparicio R. and J. Harwood, eds., Handbook of olive oil. Analysis and properties. New York (USA): Springer, p. 772.

Salas JJ, Martínez-Force E, Harwood JL, et al. 2014. Biochemistry of high stearic sunflower, a new source of saturated fats. 55: 30-42.

Segers JC, van de Sande RLKM. 1990. Degumming-Theory and Practice. In: Erickson DR, ed., Edible fats and oils processing: basic principles and modern practices. Illinois (USA): American Oil Chemists' Society, p. 449.

Seppanen C, Song Q, Saari Csallany A. 2010. The antioxidant functions of tocopherol and tocotrienol homologues in oils, fats, and food systems. J. Am. Oil Chem. Soc. 87: 469-481.

Serani A, Piacenti D. 1992. I fenomeni chimico-fisici che regolano la perdita degli steroli liberi durante la raffinazione deglioli vegetali. Riv. It. Sost. Grasse 69: 311-315.

Siger A, Nogala-Kalucka M, Lampart-Szczapa E. 2008. The content and antioxidant activity of phenolic compounds in cold-pressed plant oils. J. Food Lipids 15: 137-149.

Stevenson DE, Hurst RD. 2007. Polyphenolic phytochemicals - just antioxidants or much more? Cell. Mol. Life Sci. 64: 2900-2916.

Talal EMAS, Jiang J, Yuanfa L. 2013. Chemical refining of sunflower oil: effect on oil stability, total tocopherol, free fatty acids and colour. Int. J. Eng. Sci. Tech. 5: 449-454.

Tasan M, Demirci M. 2005. Total and individual tocopherol contents of sunflower oil at different steps of refining. Eur. Food Res. Technol. 220: 251-254.

Taylor DR. 1993. Adsorptive bleaching. In: Applewhite TH, ed., Proceedings of the world Conference on oilseed technology and utilization, Champaign, IL (USA). AOCS Press, pp. 311-319.

Taylor DR. Bleaching. 2005. In: Shahidi F, ed., Bailey's industrial oil and fat products. New Jersey (USA): Wiley, Vol. 5.

Topkafa M, Ayyildiz HF, Arslan FN, et al. 2013. Role of different bleaching earths for sunflower oil in a pilot plant bleaching system. Pol. J. Food Nutr. Sci. 63: 147-154. 
Traber MG, Atkinson J. 2007. Vitamin E, antioxidant and nothing more. Free Radic. Biol. Med. 43: 4-15.

Velasco L, Fernández-Martínez JM, García-Ruiz R, Domínguez J. 2002. Genetic and environmental variation for tocopherol content and composition in sunflower commercial hybrids. J. Agr. Sci. 139: 425-429.

Velasco L, Pérez-Vich B, Fernández-Martínez JM. 2004. Novel variation for the tocopherol profile in a sunflower created by mutagenesis and recombination. Plant Breed. 123: 490-492.

Velasco L, Fernández-Cuesta Á, Fernández-Martínez JM. 2014. New sunflower seeds with high contents of phytosterols. OCL 21: D604.

Veldsink JW, Muuse BG, Meijer MMT, Cuperus FP, van de Sande RLKM, van Putte KPAM. 1999. Heat pretreatment of oilseeds: effect on oil quality. Eur. J. Lipid Sci. Technol. 101: 244-248.

Verleyen T, Verhe R, Garcia L, Dewettinck K, Huyghebaert A, De Greyt W. 2001. Gas chromatographic characterization of vegetable oil deodorization distillate. J. Chromatogr. A 921: 277-285.

Verleyen T, Forcades M, Verhe R, Dewettinck K, Huyghebaert A, De Greyt W. 2002. Analysis of free and esterified sterols in vegetable oils. J. Am. Oil Chem. Soc. 79: 117-122.
Verleyen T, Sosinska U, Ioannidou S, et al. 2002. Influence of the vegetable oil refining process on free and esterified sterols. J. Am. Oil Chem. Soc. 79: 947-953.

Verleyen T, Szulczewska A, Verhe R, Dewettinck K, Huyghebaert A, De Greyt W. 2002. Comparison of steradiene analysis between GC and HPLC. Food Chem. 78: 267-272.

Vlahakis C, Hazebroek J. 2000. Phytosterol accumulation in canola, sunflower, and soybean oils: Effects of genetics, planting location, and temperature. J. Am. Oil. Chem. Soc. 77: 49-53.

Yang Y-K, Wang L-P, Chen L, et al. 2015. Coenzyme Q10 treatment of cardiovascular disorders of ageing including heart failure, hypertension and endothelial dysfunction. Clin. Chim. Acta 450: 83-89.

Zacchi P, Eggers R. 2008. High-temperature pre-conditioning of rapeseed: A polyphenol-enriched oil and the effect of refining. Eur. J. Lipid Sci. Technol. 110: 111-119.

Zamora R, Olmo C, Navarro JL, Hidalgo FJ. 2004. Contribution of phospholipid pyrrolization to the color reversion produced during deodorization of poorly degummed vegetable oils. J. Agric. Food Chem. 52: 4166-4171.

Zufarov O, Schmidt S, Sekretár S. 2008. Degumming of rapeseed and sunflower oils. Acta Chimica Slovaca 1: 321-328.

Cite this article as: Alicia Ayerdi Gotor, Larbi Rhazi. Effects of refining process on sunflower oil minor components: a review. OCL 2016, 23(2) D207. 